\title{
LAS PAPAS EN LOS PAÍSES EN DESARROLLO*
}

\author{
DOUGLAS E. HORTON**
}

Frecuentemente se piensa que la papa es un cultivo de las naciones industrializadas y de menor importancia en zonas en desarrollo. Sin embargo, actualmente los países en desarrollo producen un tercio de las papas a nivel mundial. En términos monetarios, las papas son su cuarto cultivo alimenticio en orden de importancia después del arroz, trigo y maíz (Tabla 1). Desde 1950, los rendimientos de la papa se han duplicado en los países en desarrollo y la producción se ha triplicado (Figura 1). La expansión del cultivo de papa ha sido rápida particularmente en África, Asia y Centroamérica.

TABLA 1. Producción de los diez cultivos alimenticios de más alto valor en los países en desarrollo, 1981/1983 $\left({ }^{4}\right)$.

\begin{tabular}{lcccc}
\hline & $\begin{array}{c}\text { Materia } \\
\text { Seca } \\
\text { (millones } \\
\text { de t) }\end{array}$ & $\begin{array}{c}\text { Energía } \\
\text { comestible } \\
\text { (billones } \\
\text { de kcal) }\end{array}$ & $\begin{array}{c}\text { Proteína } \\
\text { comestible } \\
\text { (millones } \\
\text { de t) }\end{array}$ & $\begin{array}{c}\text { Valor de la } \\
\text { producción } \\
\text { (miles de mi- } \\
\text { llones US\$) }\end{array}$ \\
\hline Arroz en cáscara & 355 & 982 & 18.1 & 68.7 \\
Trigo & 157 & 454 & 18.1 & 26.6 \\
Maíz & 134 & 476 & 12.2 & 18.5 \\
Papas & 17 & 51 & 1.4 & 11.7 \\
Camotes & 31 & 99 & 1.5 & 9.5 \\
Yuca & 51 & 109 & 0.5 & 8.9 \\
Soya & 28 & 127 & 10.8 & 6.5 \\
Sorgo & 42 & 149 & 4.9 & 5.8 \\
Maní, en cascara & 17 & 74 & 3.4 & 5.3 \\
Plátanos & 13 & 34 & 0.3 & 4.2 \\
\hline
\end{tabular}

Desde 1950, la producción de papa también se ha incrementado en la mayor parte de las zonas industrializadas - cerca de $80 \%$ en Australia y Nueva Zelandia y en más de $40 \%$ en los Estados Unidos y Canadá. La producción de papa solo ha disminuido en el oeste de Europa como resultado del cambio en la organización de la finca, aumento del precio de la papa, y reducción de la dependencia de la papa en la dieta.

\footnotetext{
*Este artículo está basado en Douglas E. Horton. 1987. Papas: Producción, Mercadeo y Programas para Países en Vías de Desarrollo. Boulder and London: Westview Press, Colorado, 1987.

Economista y Jefe del Departamento de Ciencias Sociales, Centro Internacional de la Papa (CIP)., Aptdo. 5969, Lima, Perú.
} 
Indice $1961 / 65=100$

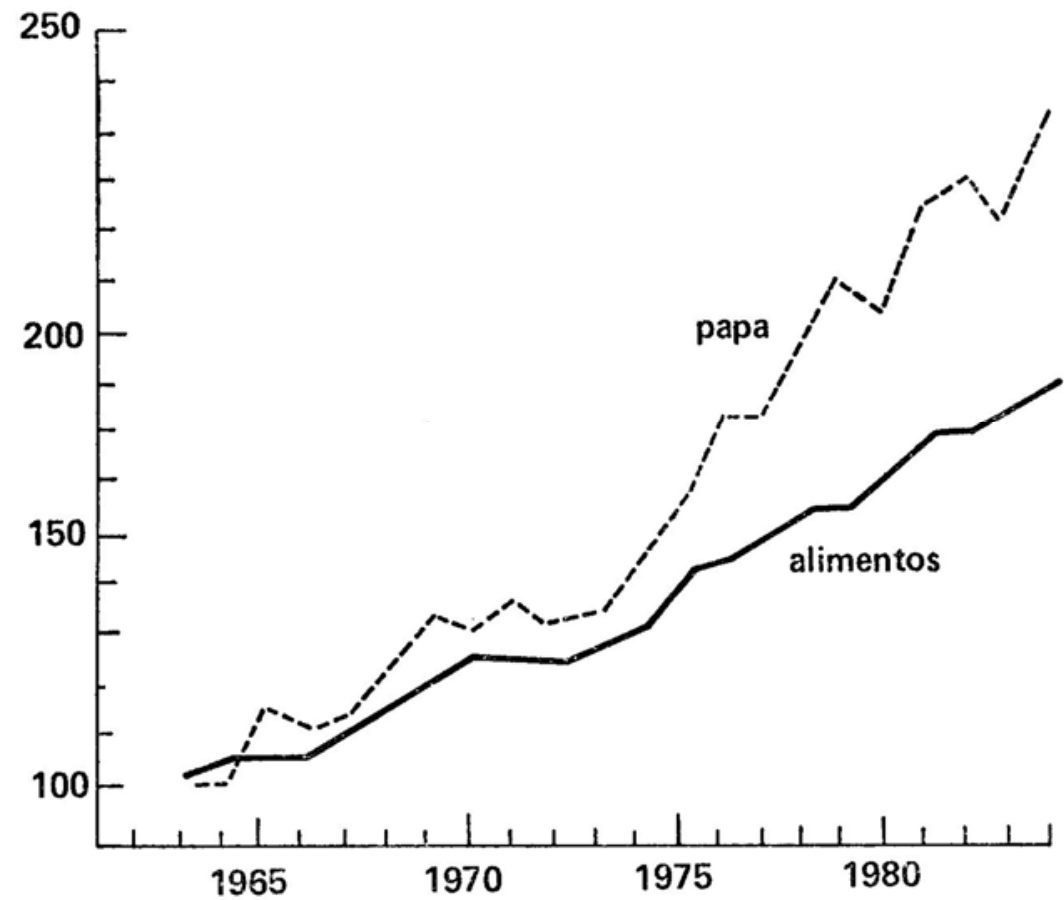

FIGURA 1.-Tendencias (promedios del movimiento de tres años) en la producción de papa y producción total de alimentos en los países en desarrollo (4).

En África, Asia y Latinoamérica las papas juegan un papel mucho más importante en el desarrollo agrícola de lo que uno se imagina. Este artículo resalta algunas de las virtudes de la papa como un cultivo alimenticio y los cambios recientes que han tenido lugar a través de la aplicación de la ciencia a la agricultura de la papa en las regiones en desarrollo.

\section{Aspectos Singulares de las Papas}

Junto con ocho especies cultivadas y más de 150 progenitores (ancentors) silvestres, la papa, es genéticamente, uno de los cultivos más complejos y variados de todos los cultivos alimenticios. Esta es una de las cualidades más notables de la papa, que le permite ser cultivada bajo una amplitud, extraordinariamente grande de condiciones ambientales. Las papas no forman tubérculos, a menos que las temperaturas nocturnas promedio estén por debajo de los 20 grados centígrados, y por esta razón no constituyen un cultivo económico en 
zonas con altas temperaturas durante todo el año. Estas son sin embargo, cultivadas en muchas tierras bajas de clima tropical con tres o cuatro meses de temperaturas nocturnas moderadas.

Los agricultores generalmente siembran una o dos toneladas de tubérculos-semilla por hectárea. La escasez y alto costo de semilla de calidad, limita la producción de papa en muchos lugares particularmente en zonas cálidas donde los insectos vectores propagan rápidamente enfermedades causadas por virus y donde los costos de almacenamiento son altos. Los rendimientos de la papa responden muy positivamente a la semilla mejorada, variedades, labranza, irrigación, fertilización y control de plagas y enfermedades. Por esta razón, los agricultores generalmente invierten más en papas por hectárea que en sus otros cultivos. Esa inversión puede ser amenazada por riesgos climatológicos, plagas y enfermedades.

La aplicación de la ciencia a las papas en las últimas décadas ha incrementado notablemente los rendimientos y reducido los riesgos de producción en muchas zonas en desarrollo. En promedio, actualmente las papas por lo general rinden más energía alimenticia por hectárea que los cereales, (Tabla 2). Debido a su alta relación proteína-caloría y a su corto ciclo vegetativo, ellas también rinden más energía y proteína comestible por hectárea y por día que los cereales y la yuca. El alto rendimiento del cultivo de papa por unidad de superficie y por tiempo es una característica especialmente valiosa en zonas en desarrollo donde el clima permite obtener en el campo más de un cultivo por año.

\section{Productores de Papa y Zonas de Producción}

Algunos de los más grandes y más pequeños, más ricos y más pobres, más progresistas y más atrasados agricultores del mundo cultivan papas. Los productores de papa para autoconsumo de las zonas montañosas aisladas de Ruanda y Bolivia se encuentran entre los agricultores más pobres del mundo. Los productores comerciales en el norte de México y Brasil están entre los más ricos. Los horticultores de mercado en ciertos lugares de Guatemala y las Filipinas cuentan con los cultivos más intensivos y productivos. Un sinnúmero de propiedades familiares, tanto rurales como urbanas, también cultivan papas conjuntamente con otros cultivos en huertos caseros. 
TABLA 2. Diez de los cultivos alimenticios con valores más altos de producción por hectárea por día en los países en desarrollo (4).

\begin{tabular}{lccccc}
\hline Cultivo & $\begin{array}{c}\text { Duración } \\
\text { del culti- } \\
\text { vo (días) }\end{array}$ & $\begin{array}{c}\text { Materia } \\
\text { seca } \\
(\mathrm{kg} / \mathrm{ha} \\
\text { día })\end{array}$ & $\begin{array}{c}\text { Energía } \\
\text { comestible } \\
(\text { 000 kcal/ } \\
\text { ha/día) }\end{array}$ & $\begin{array}{c}\text { Proteína } \\
\text { comestible } \\
(\mathrm{kg} / \mathrm{ha} / \\
\text { día) }\end{array}$ & $\begin{array}{c}\text { Valor de la } \\
\text { Producción } \\
\text { (US\$/ } \\
\text { ha/día) }\end{array}$ \\
\hline Coles & 110 & 12 & 29 & 1.6 & 27.50 \\
Tomates & 125 & 8 & 25 & 1.3 & 25.30 \\
Papas & 130 & 18 & 54 & 1.5 & 12.60 \\
Names & 180 & 14 & 47 & 1.0 & 8.80 \\
Camotes & 180 & 22 & 70 & 1.0 & 6.70 \\
Arroz, en cascara & 145 & 18 & 49 & 0.9 & 3.40 \\
Maní, en cascara & 115 & 8 & 36 & 1.7 & 2.60 \\
Trigo & 115 & 14 & 40 & 1.6 & 2.30 \\
Lentejas & 105 & 6 & 23 & 1.6 & 2.30 \\
Yuca & 272 & 13 & 27 & 0.1 & 2.20 \\
\hline
\end{tabular}

Las papas se cultivan bajo condiciones más variadas de altitud, latitud y clima que cualquier otro cultivo alimenticio de importancia - desde el nivel del mar hasta los 4.000 metros de altitud y desde el Ecuador hasta más de 40 grados norte y sur. La diversidad de zonas agroecológicas en las cuales se cultivan las papas hace prácticamente innecesaria su clasificación. Sin embargo, se pueden identificar tres zonas extremas de producción: zonas de tierras altas (incluyendo los Andes, los Himalayas, y otras zonas montañosas distribuidas en todo el África, Asia, Latinoamérica y Oceanía); zonas de tierras bajas de clima tropical y subtropical (los llanos indogángicos, desde Paquistán hasta India y Bangladesh, la costa peruana, y el norte de México); y las zonas de clima templado (sur de Argentina y Chile, la península Coreana, el norte de Turquía, y el norte de China).

En las zonas de tierras altas y de clima templado, la mayor parte de las papas son sembradas en la primavera y cosechadas en el otoño. El clima frío del invierno facilita el almacenamiento para consumo doméstico, la venta al final del año, y la siembra en la siguiente temporada. La exposición a condiciones climáticas tales como las heladas, el granizo, y la sequía son fuentes importantes de riesgos en la producción. El tizón tardío - la enfermedad fungosa que causó el fracaso del cultivo y llevó a Irlanda a una situación de hambruna en 1840 - afecta la mayoría de zonas de tierras altas y clima templado; los insectos y nematodos son un problema en algunos lugares.

En las zonas de tierras bajas, los agricultores generalmente siembran papas al comienzo de la temporada fría en zonas con irrigación o abundante humedad residual en el suelo. Las papas están expuestas a menos riesgos debidos al clima, pero a mayores plagas y enfermedades que en las zonas más frías. Las temperaturas altas del verano después de la cosecha hacen difícil el almacenamiento, y en algunos lugares se hace necesario utilizar almacenes refrigerados de 
alto costo. Debido a las altas temperaturas del ambiente y a las poblaciones de insectos, es difícil para los agricultores de tierras bajas producir y almacenar tubérculos-semillas de alta calidad, y muchos de ellos compran semilla producida en zonas de tierras altas o de clima templado. Tradicionalmente, sólo algunas de las variedades disponibles eran adecuadas para las condiciones de cultivo en las tierras bajas. Los recientes progresos en tecnología de semilla, variedades, manejo de plagas y almacenamiento han dado como resultado una expansión significativa de la producción de papa en muchas zonas de tierras bajas y clima cálido, como las llanuras de India y Bangladesh.

\section{La Papa: Mercadeo, Consumo y Nutrición}

Las proyecciones convencionales de la demanda asumen que los cambios en ingresos, precios, y hábitos alimenticios tienen poco impacto sobre la demanda por papas (2). Estudios recientes muestran que en la mayoría de países en desarrollo, los ingresos crecientes y el cambio en los hábitos de consumo, asociados con el desarrollo económico y el urbanismo, llevan a un consumo mucho mayor de papa. Mejoras en la producción y en la tecnología de postcosecha han ayudado a reducir los precios relativos de la papa lo que también ha estimulado la demanda. Como resultado de todo lo indicado, la demanda por papas en los países en desarrollo ha crecido más rápidamente que la demanda por la mayoría de otros alimentos. Desde que el consumo promedio de papa es aún menos de un cuarto del de Europa occidental (Figura 2), es muy posible que la demanda por papas continuará incrementándose rápidamente en el futuro.

Más del 98\% de las papas cultivadas en los países en desarrollo son consumidas internamente, en vez de ser exportadas. Sin embargo, en algunas regiones, como el norte de África y el Medio Este, son un cultivo de exportación importante que genera ingresos significativos de moneda extranjera (divisas).

Algunos gobiernos han intentado controlar los precios de las papas o amortiguar sus fluctuaciones comprando las papas al momento de la cosecha y almacenándolas para su venta posterior. La mayoría de estos programas han tenido muy corta vida debido a que los cambios en los precios eran difíciles de predecir, el manejo deficiente, y los costos de almacenamiento eran superiores a lo estimado. Los productores de papa, prácticamente en todas partes almacenan parte de su cosecha, ayudando a estabilizar el abastecimiento y los precios durante todo el año (1). Recientes mejoras en el almacenamiento de tubérculos-semillas en las fincas han ayudado a facilitar el flujo de papas a los mercados de consumo al 
permitir que los agricultores cultiven papas en diferentes épocas del año.

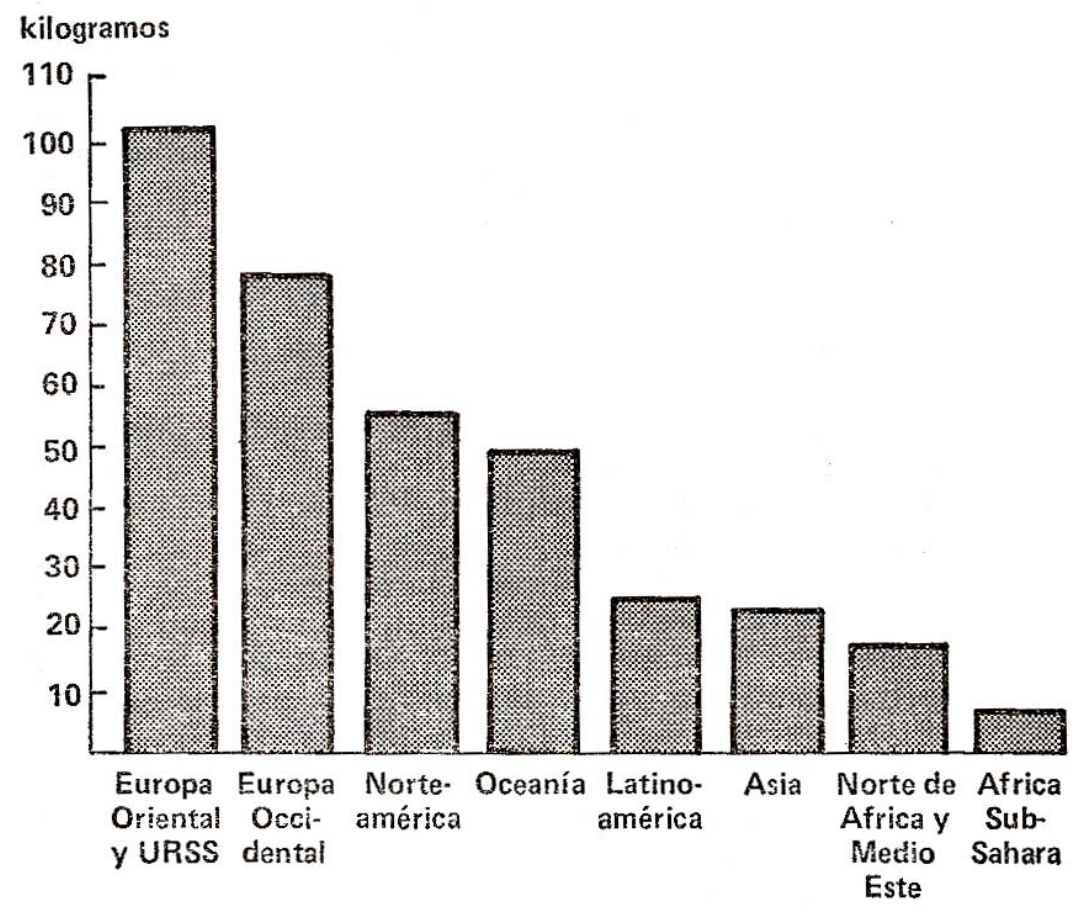

FIGURA 2.—Consumo per cápita de papa, por región 1979/84 (4).

La elaboración de almidón y alcohol de papa es poco práctico en países en desarrollo debido al alto costo relativo del tubérculo. Existen unas cuantas excepciones, tales como el norte de China y el sur de Chile, donde las papas son baratas a la cosecha pero el costo de su transporte a los mercados en las ciudades es alto. El procesamiento de la papa para consumo humano se está expandiendo rápidamente en muchos países en desarrollo para satisfacer la creciente demanda por papas fritas en hojuelas y a la francesa.

En zonas rurales, los agricultores que producen papa generalmente comen más papas que aquellos que no las producen. En pueblos y ciudades, la relación entre el nivel de ingresos y el consumo de papa depende de los precios relativos. Donde las papas son relativamente baratas, como es el caso de los Andes, el consumo más alto se encuentra en las familias más pobres. En la situación más comúnmente encontrada, donde las papas son relativamente caras, como en la mayor parte de África y Asia, el consumo de papa es más 
alto entre los grupos de mayores ingresos. La implicación es que conforme aumente el nivel de ingresos en el futuro, aumentará el consumo de papa en la mayoría de los lugares.

Contrariamente a lo que se piensa, la contribución de la papa en la alimentación humana no es energía sino en proteínas, en vitaminas $\mathrm{y}$ en minerales Woolfe (6). No obstante, que el contenido de carbohidratos y proteínas de las papas frescas es mucho menor que el de los cereales, la cocción reduce las diferencias. La papa es un producto bien balanceado en el sentido de que la relación proteína/caloría es más alta que en otros cultivos de raíces, la mayoría de los cereales, y que en los plátanos. El valor biológico de la proteína de la papa es también superior que el de la mayoría de las otras fuentes vegetales y comparable al de la leche de vaca. Su alto contenido de lisina hace de la proteína de la papa un complemento muy valioso para las dietas con base en cereales que generalmente son bajas en este aminoácido.

La papa es comparable a otras hortalizas en cuanto a su contenido en vitaminas, y es principalmente rica en vitamina C. El contenido mineral de la papa es influenciado fuertemente por la calidad del suelo donde se cultiva. Normalmente, la papa es una fuente moderadamente buena de hierro, una buena fuente de fósforo y magnesio y una excelente fuente de potasio.

\section{Programas de Papa}

La gran cantidad de información científica sobre papas existentes en los países desarrollados, los avances recientes en biotecnología, y el programa de investigación de orientación práctica del Centro Internacional de la Papa (CIP) han creado muchas oportunidades para el mejoramiento de la papa en los países en desarrollo CIP (5). Para estar en condiciones de utilizar y adaptar los resultados de la investigación llevada a cabo en los lugares más diversos, los programas nacionales necesitan una base sólida de conocimientos y pericia en cuatro áreas técnicas: mejoramiento y genética, sistemas de semilla, manejo de plagas y enfermedades y tecnología de postcosecha.

Se necesitan expertos en mejoramiento y genética para evaluar el germoplasma y seleccionar los cultivares apropiados para las condiciones locales. La pericia en sistemas de semilla es necesaria para sacar provecho de los beneficios potenciales ofrecidos por los recientes adelantos en biotecnología y métodos in vitro de eliminación de patógenos, almacenamiento y multiplicación rápida de reservas de semillas libres de enfermedades. El uso de la semilla sexual ofrece, bajo ciertas circunstancias, ventajas sobre la reproducción vegetativa, y al parecer habrá de expandirse en el futuro.

La investigación en el manejo de plagas es esencial para estudiar 
y hacer frente a problemas de plagas conforme éstos se desarrollen en el tiempo. La mayoría de los programas de investigación enfocan los problemas de producción, pero la tecnología de postcosecha también merece cuidadosa atención, debido a las grandes pérdidas de postcosecha y a la dificultad para almacenar, procesar, y transportar los tubérculos de papa los cuales contienen aproximadamente $80 \%$ de agua.

Muchas de las limitaciones para la producción de papa y su utilización son de naturaleza socioeconómica más que técnica. Los programas nacionales necesitan tener capacidad de investigación socioeconómica para diagnosticar los problemas de los agricultores y los requerimientos de los consumidores, y proveer las innovaciones institucionales necesarias con el fin de implementar los cambios tecnológicos. Por ejemplo, el aprovechamiento de las innovaciones en biotecnología puede requerir una nueva ley de semillas, organizaciones de productores y un ordenamiento de los sistemas de comercialización.

Una revisión de programas exitosos de papa revela dos factores comunes: una alta prioridad en la producción de semilla y su distribución, como también el establecimiento de objetivos específicos e implementación de estrategias que estén de acuerdo con las necesidades y recursos locales Horton (1), Portland (4). Debido a las diferencias ecológicas y socioeconómicas entre países, y entre regiones dentro de algunos países, la transferencia tecnológica en el sentido convencional no ha sido un aspecto prominente del éxito en los programas. Cada programa tiene que desarrollar soluciones adecuadas para sus propios problemas. Los programas exitosos frecuentemente utilizan principios científicos, métodos, y técnicas foráneas, pero los aspectos principales de la identificación de problemas y adaptación de la investigación tiene que ser hecha localmente.

\section{Perspectivas Futuras para la Papa}

En muchas zonas donde las papas aún son poco conocidas o sólo utilizadas ocasionalmente en la alimentación es muy posible que éstas se conviertan en una hortaliza importante. En algunas zonas donde las papas son ahora consumidas como una hortaliza, pueden convertirse en un cultivo alimenticio básico. Los investigadores y los encargados de dictar la política agrícola pueden emplear mejor el potencial inexplotado de la papa como un cultivo alimenticio implementando programas sólidos de investigación y desarrollo que incrementen la productividad de los agricultores y reduzcan los costos y riesgos unitarios. El objetivo central de un programa de papa deberá ser la identificación y solución de problemas que hacen que la papa sea cara y su producción y comercialización riesgosa. Los problemas específicos que merecen una atención prioritaria varían de acuerdo 
con el lugar y pueden cambiar con el tiempo. Esto resalta la necesidad de contar con programas bien establecidos, cuya duración esté garantizada, que se encuentren orientados a satisfacer las necesidades de una clientela específica, y que cuenten con expertos tanto en los aspectos de la producción como en los aspectos socioeconómicos.

\section{REFERENCIAS BIBLIOGRÁFICAS}

1. Booth, R. H.; Burton, W. G. 1983. Future needs in potato post-harvest technology in developing countries. Agr. Ecosyst. Envir 9: 269-280.

2. FOOD AND AGRICULTURE ORGANIZATION (FAO) . 1971. Agricultural commodity Projections. Rome, FAO.

3. Hawkes, J. G. 1978. Biosystematics of the potato. In: The potato Crop Chapman and Hall, London.

4. Horton, D. E. 1987. Potatoes: production, marketing, and programs in developing countries. Westview Press, Colorado.

5. INTERNATIONAL POTATO CENTER (CIP). 1984. Potatoes for the developing world. CIP, Lima.

6. Woolfe, J. A. 1987. The Potato in the Human Diet. Cambridge University Press, Cambridge. 